\title{
The metabolic stone evaluation: An opportunity for shared decision-making
}

\author{
Darren Beiko, MD, MBA, FRCSC \\ Department of Urology, Queen's University, Kingston, ON, Canada
}

Cite as: Can Urol Assoc J 2018;12(10):319-20. htrp://dx.doi.org/10.5489/cuai.5602

See related article on page 313

I $\mathrm{n}$ this issue of CUAJ, Harmouch et al assessed adherence to metabolic kidney stone evaluation guidelines, adequacy of physician communication of metabolic evaluation results, and patient interest in stone prevention strategies. ${ }^{1}$ The authors surveyed 530 shockwave lithotripsy treatment (SWL) patients across five Canadian institutions and found that adherence to the 2016 CUA guideline ${ }^{2}$ was suboptimal. They identified 421 patients $(79.4 \%)$ with at least one indication for a metabolic kidney stone work evaluation, yet only 176 of these patients $(41.8 \%)$ actually received a metabolic evaluation. Of the patients receiving a metabolic evaluation, $60.7 \%$ received an explanation of their results, $77.5 \%$ of which understood the explanation. Most patients (84\%) were interested in further information regarding their kidney stone disease and dietary modifications or medical therapy for secondary prevention of their kidney stone disease.

This article is very timely when considering the surging focus on quality of life issues in kidney stone disease, the increasing interest in healthcare costs and value-based healthcare, the shift to shared decision-making approaches, and initiatives such as Choosing Wisely Canada ${ }^{\mathrm{TM}}$ that affect investigation and treatment decisions in patient care.

First-time kidney stone patients face a recurrence rate of $20-50 \%$ within five years of the initial stone event. ${ }^{3,4}$ We know an acute stone event has a negative impact on a patient's quality of life, ${ }^{5}$ and with stone recurrences, urolithiasis becomes a chronic disease that negatively impacts quality of life on a long-term basis. ${ }^{6}$ Studies have shown that dietary modifications ${ }^{6}$ and medical therapy, including potassium citrate ${ }^{7}$ and thiazides, ${ }^{7}$ improve quality of life among stone formers. Furthermore, randomized controlled clinical trials have shown fluids, ${ }^{8}$ diet, ${ }^{9}$ and the use of various medications, including potassium citrate, ${ }^{10}$ thiazides, ${ }^{11}$ and allopurinol ${ }^{12}$, to effectively decrease kidney stone recurrence.
Given the above known benefits of non-surgical approaches to kidney stone disease, why are the majority of stone patients still not offered a metabolic evaluation and subsequent appropriate medical therapy? According to Bensalah et al, the answer is at least in part due to contrasting perceptions between patients and urologists; they found most stone patients would consider taking medication to avoid renal colic or a surgical intervention, whereas most urologists have the perception that most patients would prefer to avoid medication even at the cost of acute renal colic or surgical interventions. ${ }^{13}$ In his 2009 Journal of Urology editorial on Bensalah et al's paper entitled, "Are we correctly managing urinary calculi?" Matlaga asked why urologists - particularly those with an interest in endoscopic management of stone disease - do not place a greater emphasis on metabolic stone evaluation and medical therapy. ${ }^{14}$ Sadly, we do not appear to have made much progress over the past decade. The answer to Matlaga's question is likely multifactorial and related to a combination of our own lack of knowledge and comfort as physicians with the metabolic evaluation and its interpretation, our lack of comfort and familiarity of the multiple medications that may need to be prescribed and their side effect profiles, ${ }^{14}$ our own unwillingness as physicians to commit patients to lifelong medication, our lack of interest in cumbersome, long-term followup appointments (including the titration of alkali citrate doses according to urine $\mathrm{pH}$ levels), and the commonly held belief among our medical community that medical therapy is bothersome to many patients and therefore not well-tolerated. ${ }^{5}$

This study by Harmouch et al will challenge us to optimize our approach to metabolic stone disease, specifically to offer more patients a metabolic evaluation, long-term followup, and medical treatment as indicated. We can no longer ignore the evidence in the literature that secondary prevention works for kidney stone disease. And we can certainly not ignore our patients, especially as we continue to embrace shared decision-making approaches to medical treatments. As Harmouch et al and others previously have shown, ${ }^{1,13}$ the bottom line is that the majority of patients are interested in having more information on their kidney 
Beiko

stone disease and considering dietary changes and potential medical therapies.

So where do we go from here? Based on the above, the best tactic may very well be for us to use a shared decision-making approach when deciding whether or not to pursue metabolic evaluation with an individual patient. On one hand, if a given patient wants a simple approach and is committed to increasing their daily fluid intake but not interested in making dietary changes, lifestyle modifications, or taking medication every day on a long-term basis, then it may make sense to not put that patient through a metabolic evaluation since the patient is not motivated to perform a 24- or 48-hour urine collection and the patient and physician are unlikely to act on the findings. But on the other hand, if a patient is interested in doing more than simply increasing daily fluid intake to prevent stones and is prepared to act on the findings of the metabolic evaluation by committing to dietary changes, lifestyle modifications, and medical therapies as indicated, then it makes good sense for that patient to receive a metabolic evaluation. Together with patients, we can make shared decisions regarding metabolic evaluation to best meet the needs of our kidney stone patients and help prevent recurrences.

Competing interests: Dr. Beiko reports no competing personal or financial interests.

\section{References}

1. Harmouch SS, Abou-Haidar H, Elhawary H, et al. Metabolic evaluation guidelines in patients with nephrolithiasis: Are they being followed? Results of a national, multi-institutional quality assessment study. Can Urol Assoc J 2018 May 28; Epub ahead of print. hittps://doi.org/10.5489/cuaj.5155
2. Dion $M$, Ankawi $G$, Chew $B$, et al. CUA guideline on the evaluation and medical management of the kidney stone patient - 2016 update. Can Urol Assoc J 2016; 10:E347-58. https://doi.org/10.5489/cuaj.4218

3. Rule AD, Lieske JC, Li X, et al. The ROKS nomogram for predicting a second symptomatic stone episode. J Am Soc Nephrol 2014;25:2878-86. https://doi.org/10.1681/ASN.2013091011

4. Pearle MS, Calhoun EA, Curhan GC. Urologic diseases in America project: Urolithiasis. J Urol 2005; 173:84857. https://doi.org/10.1097/01.ju.0000152082.14384.d7

5. Bensalah $K$, Tuncel A, Gupta $A$, et al. Determinants of quality of life for patients with kidney stones. J Urol 2008;179:2238-43. htrps://doi.org/10.1016/i.uro.2008.01.116

6. Patel N, Brown RD, Sarkissian C, et al. Quality of life and urolithiasis: The patient-reported outcomes measurement information system (PROMIS). Int Braz J Urol 2017;43:880-6. https://doi.org/10.1590/ s1677-5538.ibju.2016.0649

7. Raffin EP, Penniston KL, Antonelli JA, et al. The effect of thiazide and potassium citrate use on the health-related quality of life of patients with urolithiasis. J Urol 2018 Jun 15; Epub ahead of print. htrps://doi.org/10.1016/i.juro.2018.06.023

8. Borghi L, Meschi T, Amato F, et al. Urinary volume, water, and recurrences in idiopathic calcium nephrolithiasis: A 5-year randomized, prospective study. J Urol 1996;155:839-43. https://doi.org/10.1016/ S0022-5347(01)66321-3

9. Borghi L, Schianchi T, Meschi T, et al. Comparison of two diets for the prevention of recurrent stones in idiopathic hypercalciuria. N Engl J Med 2002;346:77-84. https://doi.org/10.1056/NEJMoa010369

10. Barcelo $P$, Wuhl 0 , Servitge $E$, et al. Randomized double-blind study of potassium citrate in idiopathic hypocitraturic calcium nephrolithiasis. J Urol 1993;150:1761. https://doi.org/10.1016/S00225347(17)35888-3

11. Pearle MS, Roehrborn CG, Pak CY. Meta-analysis of randomized trials for medical prevention of calcium oxalate nephrolithiasis. J Endourol 1999;13:679-85. https://doi.org/10.1089/end.1999.13.679

12. Ettinger B, Tang A, Citron JT, et al. Randomized trial of allopurinol in the prevention of calcium oxalate calculi. N Engl J Med 1986;315:1386-9. https://doi.org/10.1056/NEJM198611273152204

13. Bensalah K, Tuncel A, Raman JD, et al. How physician and patient perceptions differ regarding medical management of stone disease. J Urol 2009;182:998-1004. https://doi.org/10.1016/i.juro.2009.05.025

14. Matlaga BR. Are we correctly managing urinary calculi? J Urol 2009;182:826-7. https://doi.org/10.1016/i.juro.2009.06.072

Correspondence: Dr. Darren Beiko, Department of Urology, Queen's University, Kingston, ON, Canada; darren.beiko@kingstonhsc.ca

\section{Juravinski Cancer Centre and Walker Cancer Center Uro-Oncology Forum 2019}

\section{Juravinski Cancer Centre
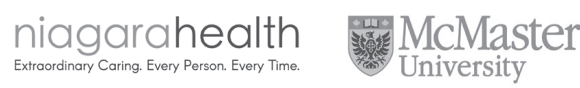

The JCC Uro-Oncology Forum will bring together experts from the Juravinski Cancer Centre and the Walker Family Cancer Centre and is set to target community urologists, medical oncologists and radiation oncologists in Ontario. Scientific sessions will focus on bladder, kidney and prostate cancers along with a research update on clinical trials.

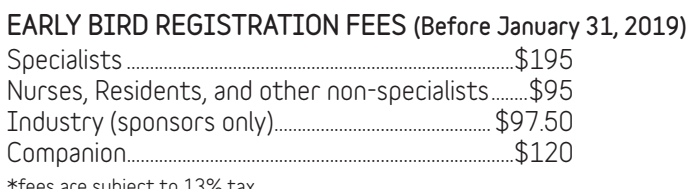

*fees are subject to $13 \%$ tax

This program is an accredited Group Learning Activity (Section 1) as defined by the Maintenance of Certification Program of the Royal College of Physicians and Surgeons of Canada, reviewed and approved by the Canadian Urological Association

CUA members can view sessions from this year's meeting at cua.org
SAVE-THE-DATE

March 1-2, 2019

Queen's Landing

Niagara-on-the-Lake, ON

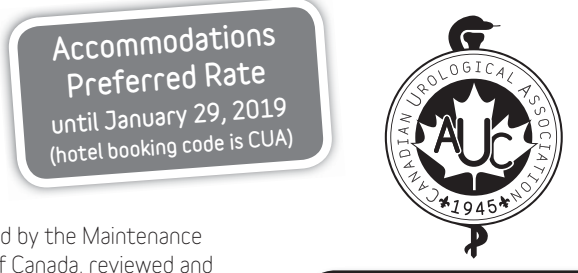

cuameeting.org 